Article

\title{
Saudi and Bahraini Mothers' Experiences of Including Their Autistic Adolescent Sons in Education: A Capabilities Approach
}

\author{
Wid Daghustani ${ }^{1}$ and Alison MacKenzie ${ }^{2, *}$ \\ ${ }^{1}$ Department of Learning and Developmental Disabilities, Arabian Gulf University, Bahrain; E-Mail: widhed@agu.edu.bh \\ 2 School of Social Sciences, Education and Social Work, Queen's University Belfast, UK; E-Mail: a.mackenzie@qub.ac.uk \\ * Corresponding author
}

Submitted: 26 May 2021 | Accepted: 25 June 2021 | Published: 13 October 2021

\begin{abstract}
Saudi Arabia and Bahrain have both signed the 2006 UN Convention on the Rights of Persons with Disabilities and have a number of acts and policies which support inclusive education for children with disabilities. However, achieving the goals of equitable education at all levels remains a challenge, especially for autistic children. This article reports on the experiences of mothers from Saudi Arabia and Bahrain in trying to find schools or autism centres for their autistic adolescent sons. The research is based on in-depth interviews with 17 mothers, the majority of whom reported that educating their sons is challenging, and that the schools and centres are inadequate or expensive, with the result that a number of participants' children had to stay at home to the detriment of the boys and their mothers' wellbeing. The findings are interpreted using the capabilities approach, a normative, evaluative framework on questions of social justice and individual flourishing. A capability evaluation reveals that many mothers experience capability corrosion as a result of gender, cultural, and legal restrictions, as well as difficulties in accessing appropriate education, with respect to three central capabilities: bodily integrity, affiliation, and control over one's environment.
\end{abstract}

\section{Keywords}

autism; Bahraini mothers; disability rights; equitable education; guardianship laws; Saudi Arabian mothers; UNCRPD

\section{Issue}

This article is part of the issue “Promoting Inclusion and Equality in Education” edited Allen Thurston (Queen's University Belfast, UK) and Tien-Hui Chiang (Anhui Normal University, China).

(C) 2021 by the authors; licensee Cogitatio (Lisbon, Portugal). This article is licensed under a Creative Commons Attribution 4.0 International License (CC BY).

\section{Introduction}

In this article we explore the challenges that mothers of adolescent autistic sons confront trying to find educational settings in Saudi Arabia and Bahrain that recognise their sons' fundamental entitlement to receive "inclusive, quality and equitable education" (United Nations Convention on the Rights of People With Disabilities [UNCRPD], 2016, Article 2). We report on three specific areas: mothers' experiences of formal support for their autistic adolescent sons in schools and autism centres; the extent to which they felt their children were included; and the barriers to their sons' inclusion. Our interest in autism stems from our research and teaching in the field of special needs education with a focus on autism, additional support for learning, and our commitment to socially just inclusion for young people who have been traditionally excluded from, or marginalised within, mainstream education and society.

The accounts were drawn from in-depth, semistructured interviews with 17 mothers, 10 from Saudi Arabia, seven from Bahrain. The two countries were chosen for comparison because one of the authors is from the Kingdom of Saudi Arabia and works in the Kingdom of Bahrain. The two countries are also closely geographically located, connected by the King Fahd Causeway, but are very different to each other with respect to their cultural and legal norms. Further, and of interest, given 
that it was a closed and restrictive country until very recently, Saudi Arabia is also attempting to liberalise its economy and relax some of its strict religious and cultural practices by allowing, for example, women to drive, the ban against which ended in 2018 . The prohibition against women driving had a significant impact on the inclusion of children with disabilities in schools, as we will demonstrate in this article. Bahrain, by contrast, is a more progressive society than Saudi Arabia, where women can fully participate in society and have almost the same rights as men, in law at least. The experiences of mothers in both countries will be contrasted to explore the extent to which their capacity to support and care for their autistic sons is enabled by the social and political structures, and disability laws and rights of their respective countries. However, because the impact of restrictions on women's rights was so far reaching, Saudi Arabia will be foregrounded.

The philosophical focus of our analysis will be on "capability opportunities" to realise "valuable functionings" in areas that are essential to human flourishing and preserving human dignity (Nussbaum, 2006). We will apply the capabilities approach, an evaluative framework concerned with issues of social justice and comparative quality-of-life assessments. Application of the approach entails a range of normative exercises on individual wellbeing, social arrangements, such as the provision of, and access to, inclusive education, and the design of social, political, or economic policies that enable or advance wellbeing and justice (Robeyns, 2016). The specific normative exercise in which we will engage will draw on Nussbaum's (2006) version of the approach, specifically on what she determines are the "ten central capabilities" (Nussbaum, 2006, pp. 76-77). Each capability is necessary for human dignity and is the answer to the question: "What is this person able to do or to be" given her circumstances? Combined, the ten central capabilities protect fundamental areas of freedom, the removal of which would render a life "not worthy of human dignity," according to Nussbaum (2011, p. 31). For the purposes of this article, we will evaluate mothers' flourishing against three of the ten central capabilities, namely: bodily integrity (no. 3), affiliation (no. 7), and control over one's environment (no. 10).

This is the first study of its kind in terms of its subject, focus, and analytical framework. There are virtually no research articles on mothers' experiences of raising adolescent autistic sons, and we could find none other than Daghustani (2019) that took a capabilities approach perspective. Research from the region on disability or autism tend to focus on the challenges associated with the condition, and children and young people's integration into schools; the research is also primarily quantitative in nature. For that reason, when we discuss our findings, we interpret them against the approach itself, rather than established research.

\section{Provision of Inclusive Education in Bahrain and Saudi Arabia: Legislation, Policy, and Planning}

The UNCRPD is the first comprehensive human rights treaty of the 21st century. The Convention marked a paradigm shift from the traditional medical model of disability to a human rights-oriented social model of disability. This shift moved away from paternalistic and assistive disability policies, whereby persons with disabilities were regarded as passive recipients of charitable interventions, to recognising them as autonomous human rights holders, capable of being full and active members of society. In 2016, UNCRPD issued General Comment No. 4 on Article 24, the right to inclusive education. Article 24.1 provides that "State Parties recognise the right of persons with disabilities to education. With a view to realizing this right without discrimination and on the basis of equal opportunity, State Parties shall ensure an inclusive education system at all levels" (UNCPRD, 2016, p. 1). The UNCRPD was ratified by Bahrain in 2007 and Saudi Arabia in 2008.

Both Saudi Arabia and Bahrain have made progress towards inclusive education systems. The Constitution of the Kingdom of Bahrain of 2002 is the primary basis for guaranteeing the rights of all groups, including persons with disabilities. Article 5(1) of the constitution stipulates the provision of "educational opportunities for every individual to develop their capabilities and skills to achieve the best of their potentials [sic] and play an active role in their society" (Bahrain's Constitution of 2002 with amendments, 2017). Article 7(10) states that that there should be diverse educational opportunities to meet the needs of all learners and "caring for students with learning and developmental disabilities by following their progress and integrating those who have the ability into the general education" (Bahrain's Constitution of 2002 with amendments, 2017).

According to UNESCO (as cited in Crabtree \& Williams, 2010, p. 200), Bahrain has "excellent integrative policies." The rights of children with disabilities to education "represent a distinct criterion of social development in this society, in keeping with equal opportunities" (Crabtree \& Williams, 2010, p. 200). In 2008 the Ministry of Education guaranteed that all students with disabilities would be included in the national education system and offered specialist provision for students with special needs with "remedial" schools for "slow learners and low achievers according to the school's need for these classes" (Ministry of Education, 2020). The Directorate of Special Education also has responsibility for finding specialist provision for students with "mental retardation" who are "deaf" and "blind" and have "speech defects" (Ministry of Education, 2020).

The most important constitutional document in the Kingdom of Saudi Arabia is The Basic Law of Governance. Article 26 of this document, for example, states that "the state shall protect human rights in accordance with Islamic Shari'ah" law, which promotes concepts of justice 
and equality and "prohibits discrimination on any basis, including disability" (Government of Saudi Arabia, 2020). The basic law also makes provision for educational services to all students with disabilities at all stages in proportion to their capabilities and needs, "as well as respecting the advanced capabilities of children with disabilities and their right to preserve their identity, and facilitating the services provided to them with continuous improvement" (Government of Saudi Arabia, 2020). One of these provisions is the inclusion of students with disabilities in mainstream schools, with supportive educational and rehabilitation services (Government of Saudi Arabia, 2020).

In Saudi Arabia, close to 750 state schools have special education classrooms that provide services for students with "mild to moderate intellectual disabilities," and "mild to moderate autism," while those with "severe disabilities" attend special schools (Aldabas, 2015). Royal Decree No. 37 (2001) approved the system of "caring for persons with disabilities" and makes a number of broad provisions, including the provision of education and educational services at all levels (from pre-school to higher education) commensurate with the capabilities and needs of persons with disabilities, and adopting laws affirming that regular schools are the natural environment for the education and teaching of "handicapped" students, into which people with disabilities should be "integrated" (Arab Committee on Human Rights, 2016, p. 60).

The language used by both ministries still tends to assume a medical approach to disability, despite the fact that both countries have signed the UNCRPD (2006), which disavows the medical model of disability. The use of deficit language (what a person is unable to do or what a person lacks) suggests that policy makers have yet to move away from describing students with disabilities in medical and deficit terms, to language that describes them as autonomous and agentic, and which reflects the individuality, dignity, and equality of the person.

\section{The Status of Women in Saudi Arabia and Bahrain}

To understand the impediments to inclusion in both countries, it is important to consider the status of women since they remain the primary carers of their children; this is particularly pertinent in Saudi Arabia. Until recently, and unlike Bahrain, sex segregation was strictly enforced in Saudi Arabia by religious police and conservative clerics to prevent any kind of "intimacy" and "informality" with unrelated men (Aart et al., 2012). To maintain moral probity, sex segregation was enforced throughout the education system and in public. Women had their own private places in almost every public institution in which they were employed and there were women's sections in restaurants, banks, airports, and charitable organisations (Daghustani, 2017). These practices are changing, however, as Saudi Arabia promotes a programme of rapid social liberalisation, prompted in part by Saudi women rights activists who began an online campaign in 2016 to end male guardianship (Thorsen \& Sreedharan, 2019). The country has slowly eased restrictions on sex segregation. Restaurants and concert halls, for example, are no longer compelled to enforce segregation. Some fundamental restrictions remain, however.

At the time of data collection (2016) the male guardianship law Al-Mahram was the most restrictive law in Saudi Arabia (indeed, in the Middle East region). Irrespective of a woman's age, marital status, education, or socio-economic status, she had to have a male guardian (mahram). A woman was the responsibility of her father or brother, and then her husband, even her son when he reached 18; if none of these relatives were available, her uncle, grandfather, nephew or any other mahram male relative would be assigned as her "protector" (Daghustani, 2017). Under the male guardianship system, women were reduced to the status of a permanent dependent minor (Aart et al., 2012). Consequently, the male guardian had, and still has, almost unlimited power over a woman, able to control her life from birth until her death. Almost every critical choice or decision a woman could make had to have the written consent of her male guardian, whether that is to obtain an education for her child or herself, marry freely, receive medical treatment, or apply for a job (Thorsen \& Sreedharan, 2019). Women are, effectively, the property of their male guardians (Hartley, 2016). While sex segregation restrictions are easing, the guardianship law means that women cannot apply for a passport or travel outside the country without the permission of her male guardian, and employers are not penalised if they request the guardians' consent to employ women. Guardianship also means that women can be trapped in abusive marriages, vulnerable to domestic violence without recourse to the law (Human Rights Watch, 2019b). According to Human Rights Watch (2019a), the state "facilitates domestic violence by granting male relatives a huge amount of control over women's lives." Indeed, the power even to control a woman's movement is, itself, "a form of domestic violence that the government enforces" (Human Rights Watch, 2019a). In the UK, it would be deemed to be "coercive control" and is against the law. As will be reported here, many of the Saudi participants in this study were denied fundamental rights because their husbands did not support of their aspirations or even those of their children.

Saudi Arabia and Bahrain are socially, religiously, and politically similar, which is unsurprising given their geographical propinquity. However, while there are restrictions and regulations which limit women's freedom and rights in Bahrain, they have significantly more freedom than do women in Saudi Arabia. Bahraini society is more pluralistic, cosmopolitan, and less tribal than other Gulf states (Singh, 2013). The Bahraini constitution, for example, states that women should be treated as equal citizens with respect to rights and duties (Singh, 2013). Saudi Arabia, by contrast, does not have a constitution as 
such; instead, the law is based on the Qur'an. Women's rights are not documented since the country relies on tradition and custom to judge what women can do and be. If the Qur'an does not address a certain subject, the clerics will tend to err on the side of caution and render it haram (forbidden). The driving ban was a good example of this kind of Qur'anic interpretation-and resulted in a powerful obstacle to gender equality and women's freedom of movement. Like Saudi Arabia, Bahrain does not have a good public transport system but does permit women to drive their own cars, an important freedom giving women mobility and access to public spheres. In this study, as we shall report, forbidding Saudi women to drive (as of 2018 they now have this right) had a surprising and far-reaching impact on their capacity to support their children's education and protect them from abuse or neglect while in school.

\section{The Capabilities Approach}

The capabilities approach is an approach to "quality-oflife assessment" and to "theorizing about social justice" (Nussbaum, 2011, p. 18). The approach entails two core normative claims: "that the freedom to achieve wellbeing is of primary moral importance" and that this freedom "is to be understood in terms of people's capabilities," or their authentic opportunities to pursue "what they have reason to value" (Robeyns, 2016) - to be educated, to enjoy supportive social relationships, or to succeed in school as a child with disabilities. The key question that a capability theorist asks is: What is this person "able to do and to be" (Nussbaum, 2011, p. 18).

The capabilities approach contrasts with other approaches to wellbeing that focus on, for example, numeric assessments of wealth (such as the GDP) or subjective accounts of happiness - these approaches cannot necessarily assess whether a society is just. The approach asks about "functionings," or various states of "doings" and "beings." "Doings" can include travelling, voting in an election, or caring for a child, aspects of life that GDP or theories of welfare cannot ask. "Beings" include being well-nourished, literate, and healthy. The approach is "pluralist" about values. This means that whatever makes any life valuable is not based on a single or total conception, such as might be described by a theocracy, a single party state, ruling elite or a community. People value different things and have different views about what makes life valuable, and the capabilities approach respects this. In contrast to functionings, capabilities "are not just abilities residing inside a person," they are "the freedoms or opportunities created by a combination of personal abilities and the political, social, and economic environment" (Nussbaum, 2011, p. 20). For example, travelling (or driving) is a functioning, the opportunity to travel (or drive) is the corresponding capabilityfreedom to travel. Functionings are the realisations of the capabilities. Underpinning the approach is a regard for the inherent dignity of, and respect for, the person, and entails, among other things, respecting that she has different goals, aspirations, outlooks, and life plans that are distinctly her own and different to what others might choose to do.

A central feature of Nussbaum's approach is the ten central capabilities which are necessary for a life "worthy of human dignity" (Nussbaum, 2011, p. 32). In brief, the ten central capabilities are: life; bodily integrity; bodily health; senses, imagination, and thought; emotions; practical reason; affiliation; other species; play; and control over one's environment (Nussbaum, 2011, pp. 33-34). Any minimally just government will ensure that the country's citizens have a "threshold level of functioning" (Nussbaum, 2011, p. 31) in each of these; and in recognising these capabilities and in providing threshold levels of functioning, the person is regarded as an end, not as a mere means to achieving another's end. What this means in practice is that the means to good health (the end) is a decent diet and access to primary health care (at least) and education. However, girls and women, in many parts of the world, must forgo both enough food to sustain good health and education for the sake of their male relatives and siblings, as well as to preserve custom. They become mere means to their male relatives' wellbeing. The capabilities are non-fungible, meaning that one capability cannot be traded for more of another, and are inter-dependent: Corrosion in one capability reduces the fertility and fertile functioning of all the rest. Thus, women who are repeatedly exposed to domestic violence and who cannot escape because the laws of her country do not permit her to flee, are vulnerable to having their bodily health corroded, which in turn will impact on the capability for emotions, defined as "being able to have attachments to things and people" and "not having one's emotions blighted by fear and anxiety" (Nussbaum, 2011, p. 33). Capability corrosion in these two areas of freedom will have repercussions for practical reason, that is, "being able to form a conception of the good and to engage in critical reflection in the planning of one's life" (Nussbaum, 2011, p. 34), and so on. Poor health, fear and anxiety, lack of control of her environment, can restrict a woman's capacity to reason about courses of action that best safeguard her dignity and protect her from harm.

\section{Research Design}

The aim of this research was to explore the experiences of mothers of autistic adolescents (12-21 years of age), including their problems with formal and informal social support, and what they regarded as good support. The research was conducted for the first author's doctoral research (Daghustani, 2017). For the purposes of this article, we report on the mothers' experiences of formal support for their autistic adolescent sons in three specific areas: in schools and autism centres; the extent to which they felt their children were included; and the barriers to their inclusion. 


\subsection{Participants}

Seventeen women volunteered to participate, ten from Saudi Arabia and seven from Bahrain. In Saudi Arabia, the mothers came from three major cities-Makkah, Jeddah, and Khobar-and one small town, Haddah. In Bahrain, because it is a small island, no cities were specified. The target age for the autistic adolescents was from 12 to 21. While sex was not a criterion to participate, it was very difficult to find mothers who had autistic daughters. Two reasons may account for this: There are fewer girls diagnosed with autism and these are societies with traditional views about girls.

The mothers were aged between 30 and 55. Only one mother was in her 50s (Fatima; see Table 1). Eight of the mothers described themselves as housewives; three were teachers and the remainder had a variety of professions, including diplomat and university administrator. The mothers and their sons were all given pseudonyms to protect their identities. It is important to note that socioeconomic status or age were rarely a guarantee against hardship or discrimination, particularly in Saudi Arabia. What was significant was gender: Merely being a woman, a mother, and a mother of an autistic child ensured that these women had difficulty getting and maintain the formal and informal support they needed.

\subsection{Recruitment}

Participants were recruited through purposive and snowball sampling. An autism centre in Makkah provided a list of names and telephone numbers of potential participants. The first author met with six mothers in person and had telephone interviews with four. Five mothers were from Makkah, three from Jeddah, one from Haddah, and one from Khobar. The mothers in Jeddah and Khobar were contacted through the author's personal contacts. The data was collected in June 2016.

When the data collection in Saudi Arabia was complete, the author contacted an autism centre in Bahrain which put her in touch with a mother who had an autistic adolescent. This participant provided the author with the numbers of other mothers who had autistic sons within the targeted age group. The author also contacted the supervisor of another autism centre who added her to a WhatsApp mothers' group. As with the Saudi mothers, the Bahraini mothers were given the choice of either meeting in person or conducting the interview by telephone. The author met four mothers in person and had telephone interviews with the other three. The interviews were audio-recorded.

Mothers were recruited through autism centres because in both countries they are privately owned. Had the mothers been recruited through the school

Table 1. Summary of participants' biographical details.

\begin{tabular}{|c|c|c|c|c|c|}
\hline Pseudonym & Children & Autistic children & Marital status & Occupation & Background \\
\hline Fatima (SA) & 5 & 2 & Divorced & $\begin{array}{l}\text { Housekeeper for an } \\
\text { all-girls' school }\end{array}$ & $\begin{array}{l}\text { Fatima is illiterate and comes from } \\
\text { an impoverished background. }\end{array}$ \\
\hline Huda (SA) & 6 & 1 & Married & Teacher & $\begin{array}{l}\text { Huda has a bachelor's degree. } \\
\text { She is financially secure. }\end{array}$ \\
\hline Nora (SA) & 6 & 1 & Married & Housewife & $\begin{array}{l}\text { Nora did not pursue her studies. } \\
\text { She lives in financial difficulty. }\end{array}$ \\
\hline Amal (SA) & 2 & 1 & Married & $\begin{array}{l}\text { Government } \\
\text { service }\end{array}$ & $\begin{array}{l}\text { Amal has a PhD. She is financially } \\
\text { secure. }\end{array}$ \\
\hline Noha (SA) & 3 & 1 & Married & Housewife & $\begin{array}{l}\text { Noha has a high-school degree. } \\
\text { She is financially secure. }\end{array}$ \\
\hline Rasha (SA) & 9 & 1 & Married & Housewife & $\begin{array}{l}\text { Rasha wanted to go university, but } \\
\text { her husband did not permit her. } \\
\text { She experiences financial difficulties. }\end{array}$ \\
\hline Nada (SA) & 2 & 1 & Married & $\begin{array}{l}\text { Principal of an } \\
\text { autism centre }\end{array}$ & $\begin{array}{l}\text { Nada has a master's degree. She is } \\
\text { financially secure. }\end{array}$ \\
\hline Asma'a (BA) & 2 & 1 & Married & Teacher & $\begin{array}{l}\text { Asma'a has a bachelor's degree. } \\
\text { She is financially secure. }\end{array}$ \\
\hline Maha (BA) & 1 & 1 & Divorced & $\begin{array}{l}\text { Government } \\
\text { official }\end{array}$ & $\begin{array}{l}\text { Maha gave up university to raise } \\
\text { her son until he was old enough } \\
\text { that she could complete her } \\
\text { degree. She is financially secure. }\end{array}$ \\
\hline
\end{tabular}

Note: SA stands for Saudi Arabia, BA is for Bahrain. 
system, the first author would have had to apply to the Ministries of Education of both countries for permission to contact the schools and submit the interview schedule for approval. This could have restricted academic and research freedom. As it was, only the owner of the centre had to give consent. Further, while both countries are making good progress towards including autistic and disabled children in mainstream schools, the majority are still educated in autism centres. An additional consideration was time and ease of recruitment: Recruiting through centres, rather than through individual schools, was quick and efficient since many mothers could be contacted through single sites.

\subsection{Data Analysis}

The interviews lasted between $\mathbf{4 0}$ minutes and almost three hours. After completing the interviews, the author wrote the first four complete interviews in Arabic. Each interview was translated from Arabic into English. The first author listened to the audio again to compare it to the English text, making additions and corrections as necessary. Because the transcription and translation of the first four interviews took so long, the author modified her approach, realising that it would take months to transcribe and translate every word of every interview. The new approach entailed listening many times to each recording and summarising the data. The extracts, however, are reported verbatim. The result was 17 sets of notes and extracts of between 5000 and 8000 words for the Saudi interviews, and between 2000 and 4000 words for those conducted in Bahrain. The Saudi transcripts and notes were longer than the Bahraini ones because the mothers experienced such acute and persistent difficulties obtaining good support for their sons.

As the most used method in qualitative data analysis approaches for identifying, describing, and interpreting themes that offer "thick descriptions" of lived experience, we adopted Braun and Clarke's (2006, p. 79) six stage-thematic analysis.

\subsection{The Ethics of Sensitive Research}

The mothers were vulnerable either because of the disability of their adolescents or the cultural norms and regulations with which they had to negotiate. Vulnerable people are those who are at heightened susceptibility to being harmed or wronged through discrimination, exploitation, disenfranchisement, and so on. Especially prone groups are women, children, people with disabilities, and ethnic and religious minorities (Andorno, 2016). The participants, Saudi mothers in particular, experienced gender discrimination, inequality, and unjust laws, rules, and regulations. Many of the mothers became upset when they described their struggles. Some cried, particularly when they expressed fears about their sons' future or expressed hope that their sons would die before them; while others seemed lost and confused about what to do in the best interests of their children against significant odds.

Ethical thinking with respect to research is "based on principles or values... theorized to guide decisionmaking" (Farrimond, 2017, p. 76). Farrimond lists a core set of ethical principles: respect for persons (autonomy, protection of the vulnerable); justice (treat people fairly); beneficence (do good); nonmaleficence (do no harm); fidelity (do not lie/fabricate, be trustworthy); and academic freedom. The first author of this article rigorously adhered to the core principles, explaining to the mothers not only the purpose of the research, but also that she hoped to raise awareness about caring for autistic children. She gained the mothers' trust by, for example, sharing her expertise on autism, suggesting resources to read, and providing the mothers with names and contact numbers of autism centres. The first author also shared her own personal experiences to help the mothers relax and confidently discuss their experiences. They were assured that confidentiality and anonymity were paramount, and that every effort would be taken not to have them identified. Evidence that these strategies worked and that the interviews were beneficial was that the mothers expressed their relief in sharing their experiences, and that the interviews were therapeutic.

\section{Findings: Barriers to Inclusion in Schools and Autism Centres}

The majority of mothers in both countries enrolled their sons in specialised autism centres, while others preferred mainstream settings in order to include their sons in the educational system. Several of the mothers had no choice but to send their sons to other countries such as Egypt and Jordan because services for autistic adolescents were unavailable or deficient. In other cases, the child had to stay at home because his parents did not have the financial means to enrol him in an autism centre (they are all run privately).

Because the mothers in Saudi Arabia had to contend with imposed immobility and the male guardianship laws, they could not access schools. Three could not take their sons to school because they could not drive, hire a driver, or did not have the appropriate consent form to enrol their sons. Fatima, who struggled with the guardianship system and sex-segregated schools, explained why she could not enrol her children in school:

I cannot enrol my children in schools without the signature of their father since he is the male guardian of the family. However, because I am in the process of getting Sak i'eala'a [an official deed, obtained from the court if the mother is a widow or divorced, to prove her marital status to have control over her children] the school accepted my older son's signature.

Nora, likewise, experienced many difficulties because of the rules and regulations in the country: 
I called the school and talked to the teacher and told him that Ahmad was very excited to come to school, and that he waits outside the house every morning for the driver to pick him up. But the teacher yelled at me and said, "We do not talk to women. Have your husband come and talk to us!" and he hung up the phone. I tried so hard to get Ahmad's father to go to school and talk to them, but he wouldn't go. So, Ahmad is at home again, and I do not know what to do.

Amal, however, circumvented some of the Saudi rules because of her good financial and social status:

I was able to ask the teachers to come to my place to discuss any concerns about Kareem. I was in regular contact with his teachers. He had about five, and they change every year.

Three of the Saudi mothers had financial difficulties and could not afford centre fees. Fatima, for example, who was paid very poorly, had to pay a driver to transport her and her five children:

I need to pay a driver to take me to work, take my daughter to university and take my other girl to the special education centre.... found a private autism centre for my son, but I cannot enrol him because of my financial situation.

\section{Rasha had similar experiences to Fatima:}

We do not have any public centres for autism. When Sami received the diagnosis, we couldn't afford to enrol him in a private centre. The centre, though, connected us to people who sponsor children in financial difficulty. I asked the principal of the centre to find us a sponsor... and I enrolled Sami in the centre. Soon after, they told me that the sponsor was not available anymore and that I had to pay.

Other mothers faced issues such as bullying, lack of learning, and teachers' lack of experience, as Huda explained:

Ali is older than his classmates. When they bully or hit him, and he defends himself by hitting back, but he gets all the blame....I don't want him to be expelled from school because he will have nowhere to go. There are no alternatives. Our education system is very poor, and all schools are the same....At least he is in a school even if he is not benefiting from it.

As an autism centre principal in Saudi Arabia, Nada advises mothers to leave the country if they have the financial resources because, in her view, Saudi Arabia does not have good schools for autistic children:

Regardless of the fact that Adel [her son] goes to an expensive private school, he was treated badly.
Once, his classmates offered him sweets in exchange for taking off his clothes, and he agreed to it. I was shocked!...I called the school, my husband went there and threatened to call the police and we found out who did it to him....We agreed not to complain if they helped to protect him.

Noha sent her son to Egypt where he got a lot of support but had to bring him back when the 2011 revolution erupted:

After Khalid returned from Egypt, I put him in a private school specialising in disabilities. I didn't take him to learn anything; I simply took him because I didn't want him to stay home....I even went to one of the autism centres and asked them to offer mothers workshops on how to deal with their children, but nothing happened. My son is 15 years old now, and still there is nothing. These centres offer only empty words.

Three of the Bahraini mothers had similar problems with respect to cost, quality, and availability of the centres. Asma'a explained that although she enrolled her son in a private preschool "they did nothing to help him." Several of the mothers believed that the autism centre was empowering their sons. Maha's son, for example, was training to be a teaching assistant because the autism centre in Bahrain recognised how well he got on with young children:

They started teaching him practical skills and when they noticed he was good with young children, they trained him to be a teacher assistant. They started giving him a monthly salary for his job, until, of course, the centre closed its doors.

\section{Discussion}

While the Bahraini mothers encountered many frustrations in finding good schools for their sons, it is fair to say that their frustrations were not as intense or as pervasive as those experienced by the Saudi mothers. Their children did not enjoy inclusive, equitable provision in accordance with the UNCRPD $(2006,2016)$, or even according to the laws and policies of the countries. They were often kept at home because there were no schools or centres for them to attend. Consequently, the ten central capabilities of the mothers and the children were compromised and resulted in a reduced range of functionings.

Because it features so strongly in the interviews with the Saudi mothers, we begin with capability no. 3, bodily integrity, defined as "being able to move freely from place to place; to be secure against violent assault, including sexual assault and domestic violence" (Nussbaum, 2006, p. 76). While Bahraini mothers have freedom of movement, Saudi mothers do not. Public transportation is under-developed, and mothers found themselves in a 
very difficult situation if they did not have a supportive husband or did not have the financial resources to hire a driver. By contrast, freedom of movement for mothers in Bahrain is such a basic liberty that the issue is not how the child will get to school, but which school their child will attend.

The absence of this capability had a major effect on mothers' lives in terms of accessing vital support. It is a capability failure when a woman must endure imposed immobility, when she cannot do something so basic as taking her son to a hospital, for example, or to school, but must rely on her husband, male guardian, or driver to take her and her children to these primary institutions, and inevitably significantly restricts her choices. Low incomes meant that some of the mothers (Fatima, Nora, and Rasha, for example) could not afford to hire a driver which increased their difficulties in getting their children to school or elsewhere. Four of the Saudi mothers had the financial means to hire a driver (including Amal and Noha), so they did not suffer from mobility issues to the extent that the less well-off mothers did and were less dependent on their husbands. However, this situation does not diminish the fact that all women were subject to a law that restricted their freedom of movement and that it is contingent good luck that some women have husbands or male relatives on whom they can rely: The capability was not universally or personally secure. In this regard, the women in Saudi Arabia do not have a threshold level of functioning with respect to bodily integrityfrequently, neither do their children. Capability failure in this domain has a direct impact on the active realisation and fertile functioning of the next capability.

Capability no. 10, control over one's environment, is defined as "being able to participate effectively in political choices that govern one's life.... Having property rights on an equal basis with others; having the right to seek employment on an equal basis with others" (Nussbaum, 2006, p. 77). Travel restrictions, sex segregation, and dependency on male guardians clearly impacted on Saudi mothers' capability to control their own environments and make decisions that authentically reflect their values and desires-what they want to do and to be. An active functioning is being able to access their sons' schools to enquire about their progress or to make a complaint, but their sex could debar them from contacting the school or receiving information they have the right to know, as Nora for example, reported. Their effective exclusion from this sphere of their sons' lives meant that they could not intervene in ways that could meaningfully support their children, not without the intervention of their husbands. Further, although both Saudi and Bahraini mothers have little control over their environment because of poor awareness about autism, effectively reducing their capacity to make informed decisions (a situation that impacts on capability no. 5, practical reasoning, being able to resolve what one ought to do), the failure to fertilise this capability is particularly acute for mothers in Saudi Arabia.
These issues, along with the male-guardianship law (which is upheld by custom, as much as by law), is also linked to capability no. 7, affiliation which is "being able to live towards each other, to recognise and show concern for other human beings, to engage in various forms of social interaction" (Nussbaum, 2006, p. 77). Again, Saudi women have no control over this law: They still need permission to marry, they can still be barred from leaving the country and divorce is more difficult to obtain for women than for men. Women still do not have the right to be the legal guardian of their children (Human Rights Watch, 2019a). In public, and within social institutions, women were disabled from equally representing themselves or their interests, including their children, or from asking for their basic human entitlements. Saudi Arabia's social arrangements mean that functioning at this basic threshold level can be very difficult when women are regarded as legal minors in law and by custom: In capability language they are not "fully human," unable to live a life worthy of human dignity. In either country, if children with disabilities are unable to find schools that respond and adapt to their needs, respect them as persons, and who see them only through the prism of the medical model of disabilities, then their children's opportunities for affiliation may mean that they are disbarred from making friends, having social contact, and simply flourishing as young human beings, who have prospects. These forms of insidious exclusion have real impacts on the wellbeing of their mothers, as they have attested in this study.

\section{Conclusion}

The value of the capabilities approach lies in highlighting how unfair social arrangements affect individual wellbeing and place barriers against achieving minimal threshold levels of functioning, such that women struggle to do and do be in ways that carry authentic value to them. Despite the legal provision of fair and equitable education, and the provision of disability rights in Saudi Arabia and Bahrain, autistic young people can struggle to find educational settings that cater to their needs (a situation that pertains in the UK and elsewhere; see UNESCO, 2020). These difficulties have ramifications for the wellbeing of their mothers, ramifications which impact corrosively on their functionings and capability opportunities. The impacts were particularly acute for participants in Saudi Arabia, primarily because of highly conservative values that placed severe restrictions on women's rights to do and to be. The ban on driving, a genderbased violation of the right of movement, was a particularly egregious example and which reverberated throughout almost all aspects of these women's lives. It remains to be seen how the liberalisation of Saudi society will improve the lives of women; but educational provision for autistic children has some way to go before it meets the standards set by the UNCRPD $(2006,2016)$. 


\section{Conflict of Interests}

The authors declare no conflict of interests.

\section{References}

Aart, P., Meijer, R., Wagemakers, J., Kanie, M., \& Glee, A. V. (2012). Saudi Arabia between conservatism, accommodation, and reform. Netherlands Institute of International Relations. https://www. clingendael.nl/sites/default/files/20120000_ research_report_rmeijer.pdf

Aldabas, R. A. (2015). Special education in Saudi Arabia: History and areas for reform. Creative Education, 6(11), 1158-1167.

Andorno, R. (2016). Is vulnerability the foundation of human rights? In A. Masferrer \& E. G. Sanchez (Eds.), Human dignity of the vulnerable in the age of rights (pp. 257-272). Springer.

Arab Committee on Human Rights. (2016). The first report by the Kingdom of Saudi Arabia submitted pursuant to article 48(1) of the Arab Charter on Human Rights. https://www.hrc.gov.sa/ar-sa/Reports/ لهيئة السنوي الهيئة/التقرير تقارير/HCRreports/Documents 1438-1437.pdf

Bahrain's Constitution of 2002 with amendments through 2017, 2017. https://www.constituteproject. org/constitution/Bahrain_2017.pdf?lang=en

Braun, V., \& Clarke, V. (2006). Using thematic analysis in psychology. Qualitative Research in Psychology, 3(2), 77-101.

Crabtree, S. A., \& Williams, R. (2010). Inclusive education and children with disabilities in the Gulf cooperation member states. In A. E. Mazawi \& R. G. Sultana (Eds.), Education and the Arab "world": Political projects, struggles and geometries of power (pp. 196-213). Routledge.

Daghustani, W. (2017). Journeys of mothers with autism in Bahrain and Saudi Arabia: Issues of justice? [Unpublished doctoral dissertation]. University of Glasgow.

Daghustani, W. (2019). Outside the margins: A capabilities approach to understanding mothers' experiences education services for their autistic adolescent sons in Saudi Arabia and Bahrain. International Journal of Educational Research, 94, 113-121.

Farrimond, H. (2017). The ethics of research. In D. Wyse,
E. Smith, L. E. Suter, \& N. L. Selwyn (Eds.), The BERA/SAGE handbook of educational research (pp. 72-89). SAGE.

Government of Saudi Arabia. (2020). Rights of people with disabilities. https://www.my.gov.sa/wps/ portal/snp/careaboutyou/RightsOfPeopleWith Disabilities

Hartley, M. (2016, August 10). Politics and culture: Masters and slaves. Mick Hartley: Politics and Culture. http://mickhartley.typepad.com/blog/2016/08/ masters-and-slaves.html

Human Rights Watch. (2019a). Saudi Arabia: 10 reasons why women flee. https://www.hrw.org/news/2019/ 01/30/saudi-arabia-10-reasons-why-women-flee

Human Rights Watch. (2019b). Saudi Arabia: Important advances for Saudi women. https://www.hrw. org/news/2019/08/02/saudi-arabia-importantadvances-saudi-women

Ministry of Education. (2020). Website of special education directorate. http://www.moedu.gov.bh/ SpecialEdu/?lang=ar

Nussbaum, M. C. (2006). Frontiers of justice: Disability, nationality, species membership. Harvard University Press.

Nussbaum, M. C. (2011). Creating capabilities: The human development approach. Harvard University Press.

Robeyns, I. (2016). The capability approach. In E. N. Zalta (Ed.), The Stanford encyclopedia of philosophy. https://plato.stanford.edu/archives/win2016/ entries/capability-approach

Singh, G. (2013). Women in the Gulf: An assessment of Bahrain and Saudi Arabia. Scholar's Press.

Thorsen, E., \& Sreedharan, C. (2019). \#EndMaleGuardianship: Women's rights, social media and the Arab public sphere. New Media \& Society, 21(5), 1121-1140.

United Nations Convention on the Rights of People With Disabilities. (2006). United Nations convention on the rights of people with disabilities. Optional Protocol.

United Nations Convention on the Rights of People With Disabilities. (2016). United Nations convention on the rights of people with disabilities. General comment no 4, Article 24: Right to inclusive education, C/GC/4.

UNESCO. (2020). Inclusion and education: All means all (Global education monitoring report). https://en. unesco.org/gem-report/report/2020/inclusion

\section{About the Authors}

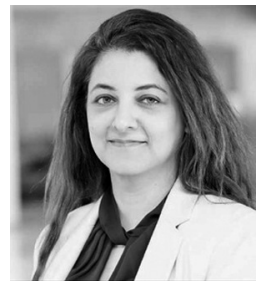

Wid Daghustani is head of Department of Learning and Developmental Disabilities at the Arabian Gulf University, Bahrain (AGU), with autism as her area of speciality. Her research foci include vulnerable and marginalised groups, special education, social justice, and research ethics. Wid is a member of Bahrain Association for Intellectual Disability and Autism and is also an editorial board member of the International Journal of Educational Research Open. 


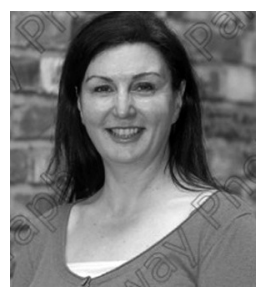

Alison MacKenzie, senior lecturer, is in the School of Sociology, Education and Social Work at Queen's University Belfast (QUB). She is the director of the programme Masters in Special Needs Education and Inclusion. Alison's research interests include social justice for marginalised groups, epistemic injustice, epistemology of ignorance and deceit, and children's rights. She is a member of the Centre for Children's Rights at QUB and supports CARA as a mentor for Syrian refugees in Turkey. 